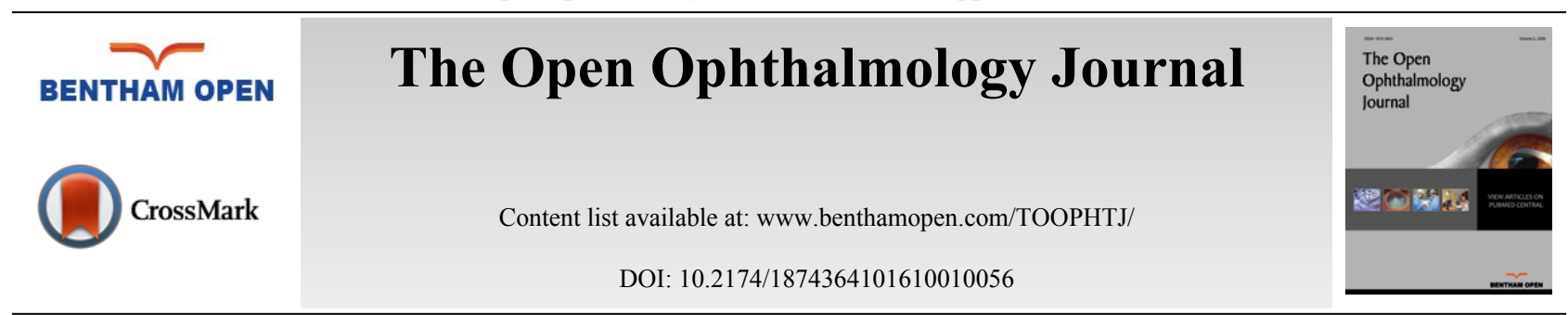

\title{
Current and Future of Laser Therapy in the Management of Glaucoma
}

\author{
Feyzahan Ekici, Michael Waisbourd and L. Jay Katz* \\ Glaucoma Research Center, Wills Eye Hospital, Philadelphia, PA, USA
}

\begin{abstract}
There has been tremendous progress in the past decades in the utilization of lasers for treating patients with glaucoma. This article reviews the use of lasers in different areas of glaucoma, including the shift from argon laser trabeculoplasty (ALT) to selective laser trabeculoplasty (SLT), laser trabeculoplasty as an initial treatment for glaucoma, new laser trabeculoplasty procedures under investigation, and other recent laser treatment modalities such as endoscopic cyclophotocoagulation and laser-assisted deep sclerectomy.
\end{abstract}

Keywords: Cyclophotocoagulation, glaucoma, laser iridotomy, laser trabeculoplasty, laser treatment.

\section{INTRODUCTION}

Glaucoma is one of the leading causes of irreversible vision loss worldwide, and the use of lasers in the treatment paradigm of this blinding disease is constantly increasing. Lasers can be employed in several ways to treat glaucoma: targeting the trabecular meshwork, thereby reducing intraocular pressure (IOP); performing laser peripheral iridotomy (LPI) and preventing pupillary block; ablating the ciliary processes and reducing production of aqueous humor; and facilitating surgical procedures such as trabeculectomy.

This articles reviews the current techniques and developments of laser therapy in the management of glaucoma.

\section{LASER TRABECULOPLASTY}

\section{Argon Laser Trabeculoplasty (ALT)}

ALT was firstly described by Wise and Witter in 1979. They speculated that the argon laser causes a thermal effect on the trabecular meshwork, resulting in stretching and widening of areas adjacent to the laser applications. This allows for an increase of outflow from the trabecular meshwork into Schlemm's canal, resulting in a reduction of IOP [1]. Further studies have suggested different mechan-isms of action for ALT, including increased phagocytotic activity [2] and decreased resistance to outflow caused by increased DNA replication of cells and increased metallo-proteinase levels within trabecular meshwork $[3,4]$.

ALT is mostly performed for patients with primary open-angle glaucoma (POAG), pseudoexfoliation glaucoma (PXF) and pigmentary glaucoma (PG) - either as an adjunct to medical therapy, or as a first-line treatment.

IOP is typically lowered by $20-30 \%$ in $75-85 \%$ of patients treated by ALT. The efficacy of this procedure, however, diminishes over time by $50 \%$ over 5 years and $32 \%$ over 10 years [ $5-7]$.

Repeat ALT success rates, after an initial successful ALT, are not promising. Repeat ALT success rates range from $21 \%$ to $70 \%$, with additional decreased success over time [5]. Agarwal et al. reported that primary ALT controlled IOP in $65 \%$ of eyes after 5 years but only in $10 \%$ of eyes when ALT was applied secondarily [8].

\footnotetext{
* Address correspondence to this author at the Wills Eye Hospital, 840 Walnut Street, Suite 1110, Philadelphia, PA 19107, USA; Tel: 215-928-3190; Fax: 215-928-3225; E-mail: ljaykatz@willseye.org
} 
Acute elevation of IOP immediately after treatment, the most common complication of ALT, occurs in up to $30-50 \%$ of treated patients [9]. The frequency of peripheral anterior synechia could be as high as $33 \%$. Other complications include persistent inflammation, and rarely hyphema or corneal abrasions [10].

\section{Selective Laser Trabeculoplasty (SLT)}

SLT, first described by Latina and Park in 1995, utilizes Q-switched frequency-doubled 532-nm Nd:YAG laser with a spot diameter of $400 \mu \mathrm{m}$, power range of $0.2-2.0 \mathrm{~mJ}$ and pulse duration of $3 \mathrm{~ns}[11,12]$. This selective photothermolysis with marked absorption by melanin pigment granules employs lower energy compared to ALT and can selectively ablate the pigmented cells of the trabecular meshwork without thermal damage to the surrounding of non-pigmented cells (Fig. 1) [13]. The efficacy and safety of SLT has been demonstrated in many prospective studies [14 - 17]. In patients who received SLT, a success rate over 70\% was achieved up to 30 months after treatment [17].

Although SLT is commonly suggested for the management of certain subtypes of open angle glaucoma (e.g. POAG, PXF, PG), researchers have studied SLT efficiency in other types of glaucoma, such as normal tension glaucoma [18, 19]. In normal tension glaucoma, patients' mean IOP decreased from 14.3 to $12.2 \mathrm{mmHg}$, and IOP fluctuation ameliorated following SLT treatment [18]. Researchers have also studied the efficiency of SLT in the prevention of steroid induced glaucoma. When SLT was applied before intravitreal triamcinolone injection, none of the patients required additional antiglaucomatous medication, whereas $50 \%$ of the untreated group required medications [19].

Compared to ALT, SLT may be repeated several times if needed, most likely due to lesser thermal damage to the trabecular meshwork and thus less scar formation. Hong et al. reported that performing repeatedly at 360 degrees SLT procedure is safe and effective after an initially successful 360 degree SLT has failed [20]. Russo et al. found repeated SLT to be better than ALT in lowering IOP [21]. Repeat SLT is considered by some as safe and effective as the initial SLT procedure [22].

Given the general poor adherence with glaucoma medications, SLT is a viable alternative as a first-line treatment for glaucoma patients. This treatment strategy has been shown to be as effective as using prostaglandins and more cost efficient compared to IOP-lowering medications [23, 24].
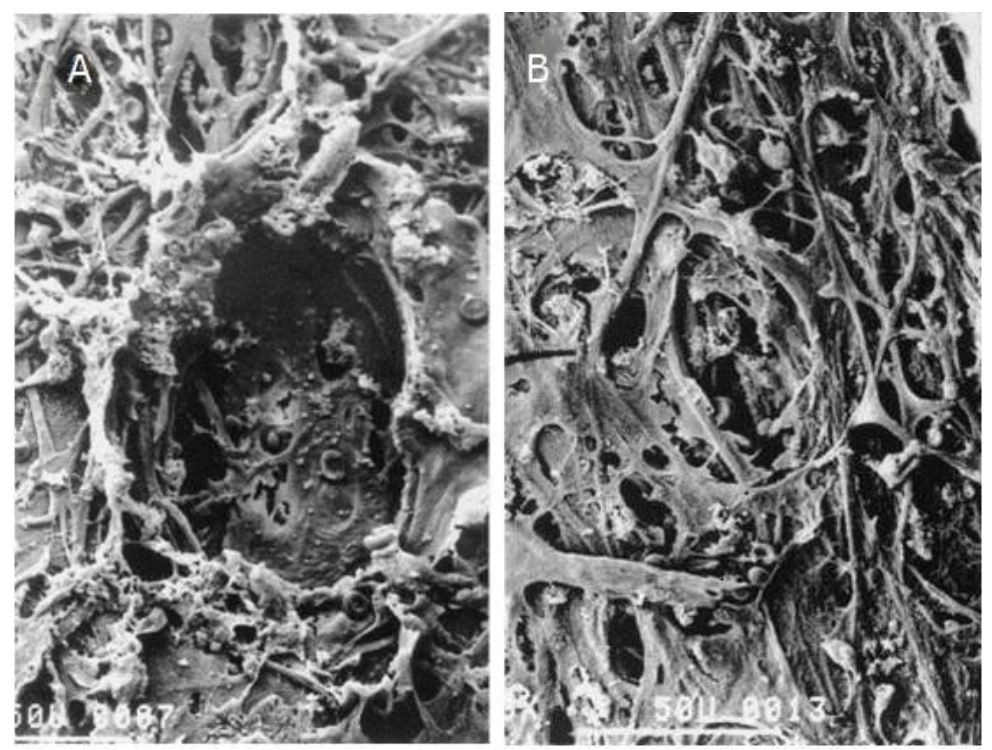

Fig. (1). Electron microscopy of trabecular meshwork treated by Argon Laser Trabeculoplasty (A) and Selective Laser Trabeculoplasty (B). As opposed to the crater created by the coagulative damage of the ALT, the SLT did not alter the architecture of the trabecular meshwork (modified from 13, with permission, photo by courtesy of Elsevier).

Melamed et al. reported a mean IOP reduction of 30\% in SLT treated patients and only $7 \%$ of these patients required additional medications after 18 months [25]. Mcllraith et al. found that initial SLT and latanoprost yielded similar outcomes: IOP reduction of 31\% in 1 year [26]. Similarly, Nagar et al. found that initial 360 degree SLT and latanoprost were equally effective. In this study, more than $80 \%$ of eyes treated with 360 degree SLT had an IOP 
reduction of $20 \%$ or more [27]. The SLT/Med study, a multicentered, prospective, randomized study, by Katz et al., recently reported IOP reduction of $26.4 \%$ in the SLT group and $27.8 \%$ in the medical treatment group. The need for additional treatment rate due to failure was higher in the medical arm of this study (24\% vs $11 \%)$ [28].

Given its efficacy, safety, repeatability and potential cost savings, it may be prudent to suggest SLT as an alternative to medications when discussing treatment options with a newly diagnosed glaucoma patient.

\section{Micropulse Diode Laser Trabeculoplasty (MDLT)}

MDLT was first described by Ingvoldstad et al. in 2005 [29]. This technology employs subvisible repetitive short diode $(810-\mathrm{nm})$ laser pulses to the trabecular meshwork. Each pulse is spaced by a long relaxation time so that surrounding tissue reaches sublethal temperature and remains viable. Similar to SLT, MDLT does not cause coagulative damage to the trabecular meshwork and laser-related complications such as IOP spikes, pigment dispersion and serious inflammatory response are minimal [29 - 31].

In a pilot study, MDLT was found as effective as ALT after 3 months [29]. Another study reported a success rate of $75 \%$ using MDLT, with mean IOP reduction of $22.1 \%$ at the end of 1 year [32]. The percentage of eyes with an IOP drop $\geq 20 \%$ was recently shown to be significantly lower with MDLT compared with ALT [33]. MDLT was suggested as a safe treatment modality with minimal anterior segment inflammation [30], however, further studies are needed to compare its efficacy with other laser treatment modalities, such as SLT.

\section{Titanium Sapphire Laser Trabeculoplasty (TLT)}

TLT uses near infrared energy $(790-\mathrm{nm})$ in pulses that last 5-10 $\mu$ s and have a spot size of $200 \mu \mathrm{m}$. Initial results indicate that TLT yielded similar IOP reduction, compared with ALT and SLT, but IOP rise after treatment was also reported $[34,35]$. In a study comparing ALT with TLT, both groups of patients achieved similar decreases in IOP over 15 months. In each group 11\% of patients had IOP spikes (defined as an increase of IOP of $6 \mathrm{mmHg}$ or more) after treatment [35]. Although TLT seems like another promising laser treatment modality, long term outcomes and possible complications should be further investigated.

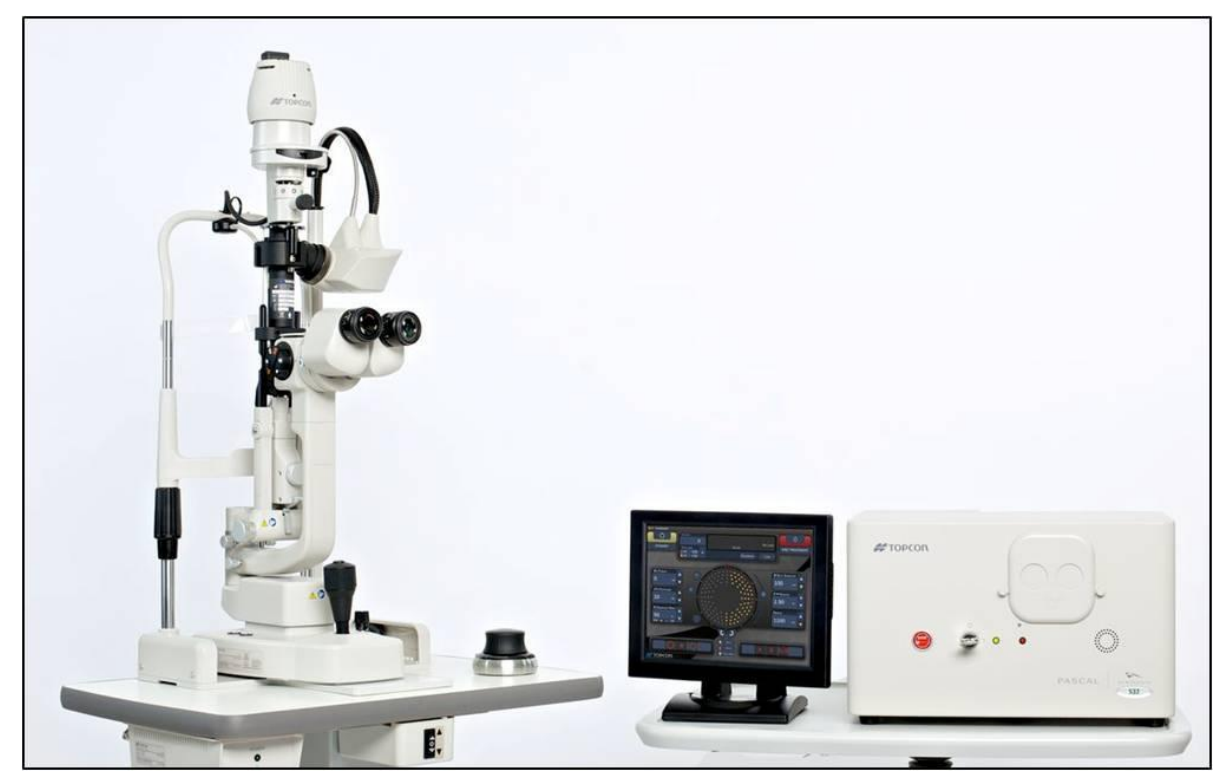

Fig. (2). Pattern Scan Laser (PASCAL) unit with Pattern Scan Laser Trabeculoplasty (PSLT) module (photo courtesy of Topcon).

\section{Pattern Scan Laser (PASCAL)Trabeculoplasty (PLT)}

The PASCAL Photocoagulator (OptiMedica Inc., Santa Clara, CA) was introduced in 2006 for semi-automated photocoagulation of the retina [36]. This computer-guided technology (Fig. 2) uses short pulse durations (10 to $20 \mathrm{ms)}$ and predetermined patterns of spots, which results in reduction of thermal diffusion and surrounding tissue damage. In a recent experimental study, PLT resulted in less thermal damage than ALT, but did not effectively prevent late scarring of the trabecular meshwork [37]. A pilot study found a $24 \%$ reduction in IOP, without IOP spikes or inflammation, over 
6 months of follow-up [38].

\section{LASER PERIPHERAL IRIDOTOMY (LPI)}

LPI has been widely used to treat angle-closure for over 20 years [39]. This procedure is used to prevent or treat pupillary block in conditions such as acute angle closure glaucoma (AACG), fellow eye of a patient with AACG, chronic angle closure glaucoma (CACG), primary angle closure suspect (PACS) and miscellaneous conditions such as pigmentary dispersion syndrome, phacomorphic glaucoma, aqueous misdirection, nanophthalmos, and plateau iris syndrome.

LPI can be performed using an argon laser or a neodymium:yttrium-aluminium-garnet (Nd:YAG) laser. LPI with $\mathrm{Nd}$ :YAG laser is typically preferred because it is simpler to apply with fewer applications and may be more tolerable for patients. It also uses less energy and has lower closure rates [40]. On the other hand, argon LPI is less likely to cause hyphema since it is thermal and therefore coagulative and may be preferred in patients who are using anticoagulant medications or have visible iris vessels that are more prone to bleeding [12]. A disadvantage of argon LPI is the use of high levels of cumulative energy to create the iridotomy, and thus causing more inflammation and corneal endothelium decompensation [41]. In patients with dark and thick irides, either the combination of argon and Nd:YAG laser or pretreatment with $532 \mathrm{~nm}$ continuous-wave Nd:YAG laser were found useful to decrease the amount of energy needed for LPI $[42,43]$.

Disturbing visual symptoms such as diplopia, transient blurring, glare, shadows, lines and ghost images have been reported after LPI [44]. The frequency of visual side effects and the relationship with the location of the iridotomy was widely studied in the literature. Spaeth et al. reported that visual symptoms related to LPI occurred in $7 \%$ of the patients and were more likely to occur in patients who had partially or fully exposed laser iridotomies than in those whom the iridotomy was completely covered by the lid. Additionally, laser iridotomies appeared to be more likely to cause symptoms when they were partially exposed than when they were fully exposed [45]. Similarly, Murphy et al. suggested that when the iridotomy was fully covered or fully exposed, symptoms disappeared [46]. In a recent study, temporally placed LPI was less likely resulted in linear dysphotopsia as compared with superior placement [47] (Fig. 3). Many physicians are now placing the LPI temporally in common practice.

Recently, cataract extraction has been suggested as an alternative therapy to LPI in patients with primary angle closure (PAC). Lam et al. reported better IOP control with early cataract surgery compared with LPI [48]. Husain et al. confirmed these findings with a prospective randomized trial with 2 year follow-up (cumulative survival $89.5 \% \mathrm{vs}$ $61.1 \%$ for the cataract surgery $v s$ LPI) [49]. The effectiveness of early lens extraction with intraocular lens implantation for the treatment of primary angle-closure glaucoma (EAGLE) Study Group compared lens extraction and LPI in newly diagnosed PAC or PACS [50]. The main outcomes of this study included IOP, quality of life and cost effectiveness. This study is still in progress and the results may lead to a shift in the current practice.

\section{LASER IRIDOPLASTY (LI)}

LI employs photocoagulative ablation to the peripheral iris. With the thermal energy applied, the stroma of the iris contracts and the angular recess widens (Fig. 4). The indications for LI included plateau iris syndrome, angle closure in nanophthalmos, and preparation for laser trabeculoplasty when iridocorneal angle is narrow and difficult to visualize [51]. After instillation of a miotic, argon or diode laser spots are applied to the iris periphery to induce widening of the angle.

Several studies found LI to be as effective or even more effective than conventional systemic and topical medications in reducing IOP levels in AACG and phacomorphic angle-closure [52 - 54]. Additionally, LI was highly effective in eliminating residual appositional closure, caused by plateau iris syndrome, after laser iridotomy. With a single laser application, 85-90\% of angles remained open for up to 10 years of follow-up [55]. Complications of LI included mild iris inflammation, iridolenticular or angular synechiaes, iris atrophia, atonic pupils and rarely corneal endothelial burns [51]. Additionally, Urrets-Zavalia syndrome, which is characterized by prolonged mydriasis unresponsive to pilocarpine, is an uncommon complication of argon LI that typically resolves spontaneously within 1 year [56].

\section{ND:YAG LASER GONIOPUNCTURE}

Laser goniopuncture is an adjunctive procedure for non-filtering glaucoma surgery such as viscocanalostomy, deep 
sclerectomy and canaloplasty. Laser goniopuncture employs tiny holes by using an Nd:YAG laser. It augments aqueous outflow through the trabeculo-Descement window when greater IOP lowering is required or when a bleb begins to fail, with no need of additional incisional surgery [57, 58]. In a study of 258 eyes undergoing deep sclerectomy or combined cataract and deep sclerectomy, a single goniopuncture procedure achieved a $20 \%$ IOP reduction, and was stable for at least 2 years in about 50\% of cases [59]. Alp et al. reported the results of Nd:YAG laser goniopuncture after viscocanalostomy: mean IOP reduced from $26.0+/-4.6 \mathrm{mmHg}$ to $11.5+/-4.0 \mathrm{mmHg}$ immediately after the procedure [60]. Laser goniopuncture complications include hyphema, iritis, peripheral synechia, iris incarceration, hypotony and late bleb leak, however, complication rates are generally low. Goniopuncture can be easily performed in office settings and appears not to interfere with the high safety profiles of nonfiltering glaucoma surgeries [57].

\section{EXCIMER LASER TRABECULOTOMY (ELT)}

The principle of ELT technology is to enhance the aqueous outflow by creating microperforations in the trabecular meshwork and the inner wall of the Schlemm's channel [58]. This device uses a xenon chloride excimer laser $a b$ interno with a duration of $80 \mathrm{~ns}$ and a wavelenghth of 308-nm. ELT is regarded as a minimally invasive glaucoma surgery with minimal thermal effect on trabecular meshwork [61]. Babighian et al. observed a mean IOP reduction of $31 \%$, and an IOP reduction of $20 \%$ or greater in $90 \%$ of cases with clinically insignificant complications [62]. In a more recent study, the same research group compared ELT with SLT (180 degree treatment). Complete success rate (when IOP was lowered by $\geq 20 \%$ with no additional glaucoma medical, laser, or surgical therapy) were $53.3 \%$ for the ELT group and $40 \%$ for the SLT group, whereas qualified success rates (when IOP was lowered by $\geq 20 \%$ with or without additional glaucoma medical, laser, or surgical therapy) were 33.3\% for the ELT and 26.6\% for the SLT group. Mean IOP decreased by $29.6 \%$ in the ELT group and by $21 \%$ in the SLT group [63]. Laser spots were applied on the trabecular meshwork either alone or combined with cataract surgery via an endoscope or gonio lens. When employed alone, a $22 \%$ IOP reduction was achieved in the ELT and a $26.7 \%$ reduction when combined with phacoemulsification. Failure rate was higher in the alone ELT group [64]. Töteberg-Harms et al. reported 1-year results of 28 eyes treated with ELT combined with cataract surgery and a 34.7\% mean IOP reduction was achieved [65].

Advantages of ELT included $a b$ interno approach spares conjunctiva for future incisional surgeries and there is low incidence of complications. The disadvantages of ELT included the requirement of an operating room in sterile conditions, highly advanced equipment, an experienced surgeon and the procedure may not be repeatable [63].

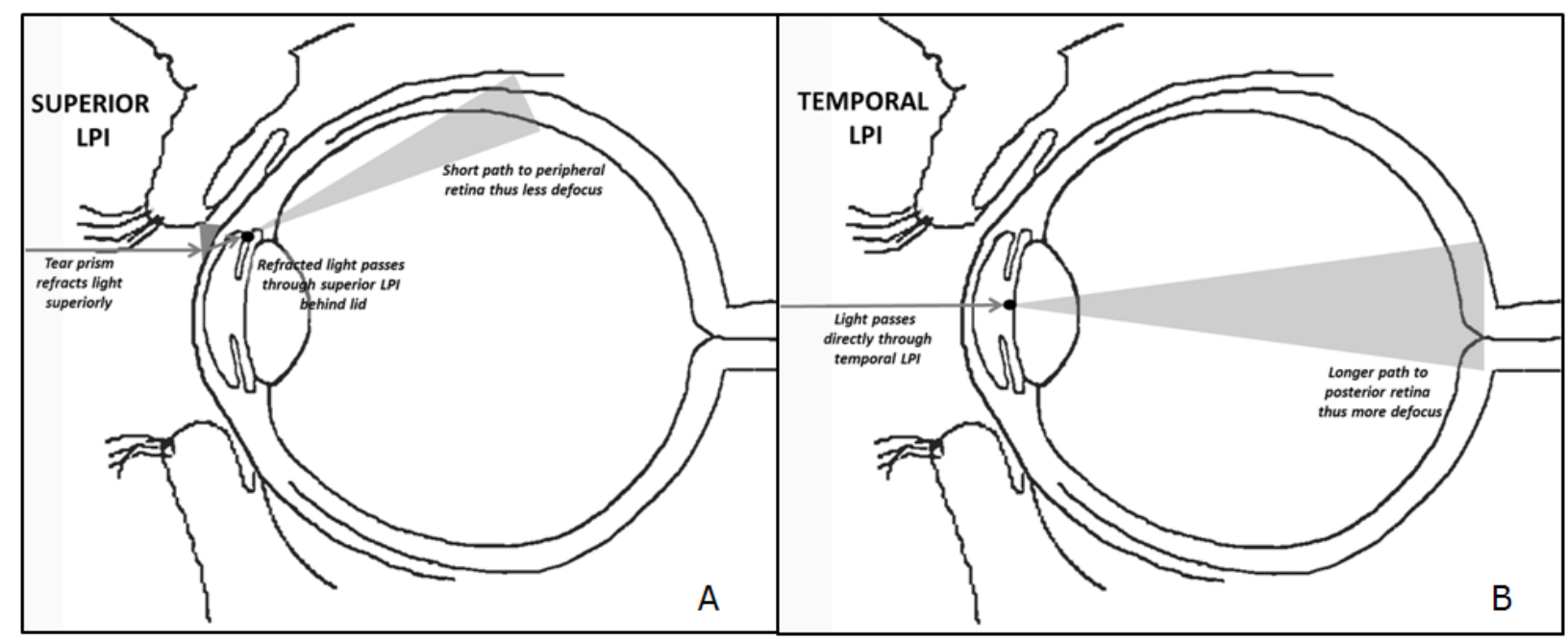

Fig. (3). Schematic eye showing that light redirected superiorly (A) by the tear prism could pass through a superior laser peripheral iridotomy (LPI) otherwise hidden by the upper lid and would strike the superior peripheral retina after a short path, thus remaining relatively focused, and light passing through a temporal (B) laser peripheral iridotomy (LPI) would continue in a straight line toward the temporal posterior pole following relatively longer path, creating a defocused image (from 47, with permission, photo by courtesy of Elsevier).

\section{LASER CYCLOPHOTOCOAGULATION}

Cyclophotocoagulation procedures have traditionally been reserved for glaucoma patients who are resistant to or not 
candidates for medical or surgical therapies, or are blind and suffer from eye pain due to end-stage diseases, especially neovascular glaucoma [66]. Recently with the improvement in technology, physicians have more experience with different types of cyclophotocoagulations (i.e. endoscopic cyclophotocoagulation), therefore, complication rates are lower than once believed and these procedures no longer may reserved only for patients not candidates for medical or surgical therapy or having end-stage glaucoma.

\section{TRANSSCLERAL CYCLOPHOTOCOAGULATION (TSCPC)}

TSCPC was introduced by Vucicevic et al. and is a method that aims to diminish IOP by the destruction of ciliary processes and thus reducing the production of aqueous humor. TSCPC employs the laser energy directly across conjunctiva and sclera with no visualization of the ciliary body [67]. This procedure can be applied using either a ND:YAG or diode laser and the effect on the tissue is mainly coagulative. Mild complications included reactive iritis, conjunctival edema and transient pain. Phthisis bulbi, permanent hypotony and anterior segment hemorrhages are serious complications reported in the literature [12]. Sympathetic ophthalmia is another rare and serious complication [68] with an incidence estimated at $0.07 \%$ after TSCPC [69]. The success rates reported are highly variable and mostly dependent on the level of energy used, however, higher energy levels increase the rate of complications. TSCPC results in a $35-45 \%$ IOP reduction and a 50\% decreased need for pretreatment medications [70]. The effectiveness of the treatment correlates with age, previous surgical procedures and the type of glaucoma. Better results are achieved in open angle, inflammatory and neovascular subtypes of glaucoma, however, repeated treatments are often necessary [71].

TSCPC is used mostly for glaucomas refractory to medical and surgical treatments and should be applied with great care for patients with useful vision and when access to other conservative treatments is limited.

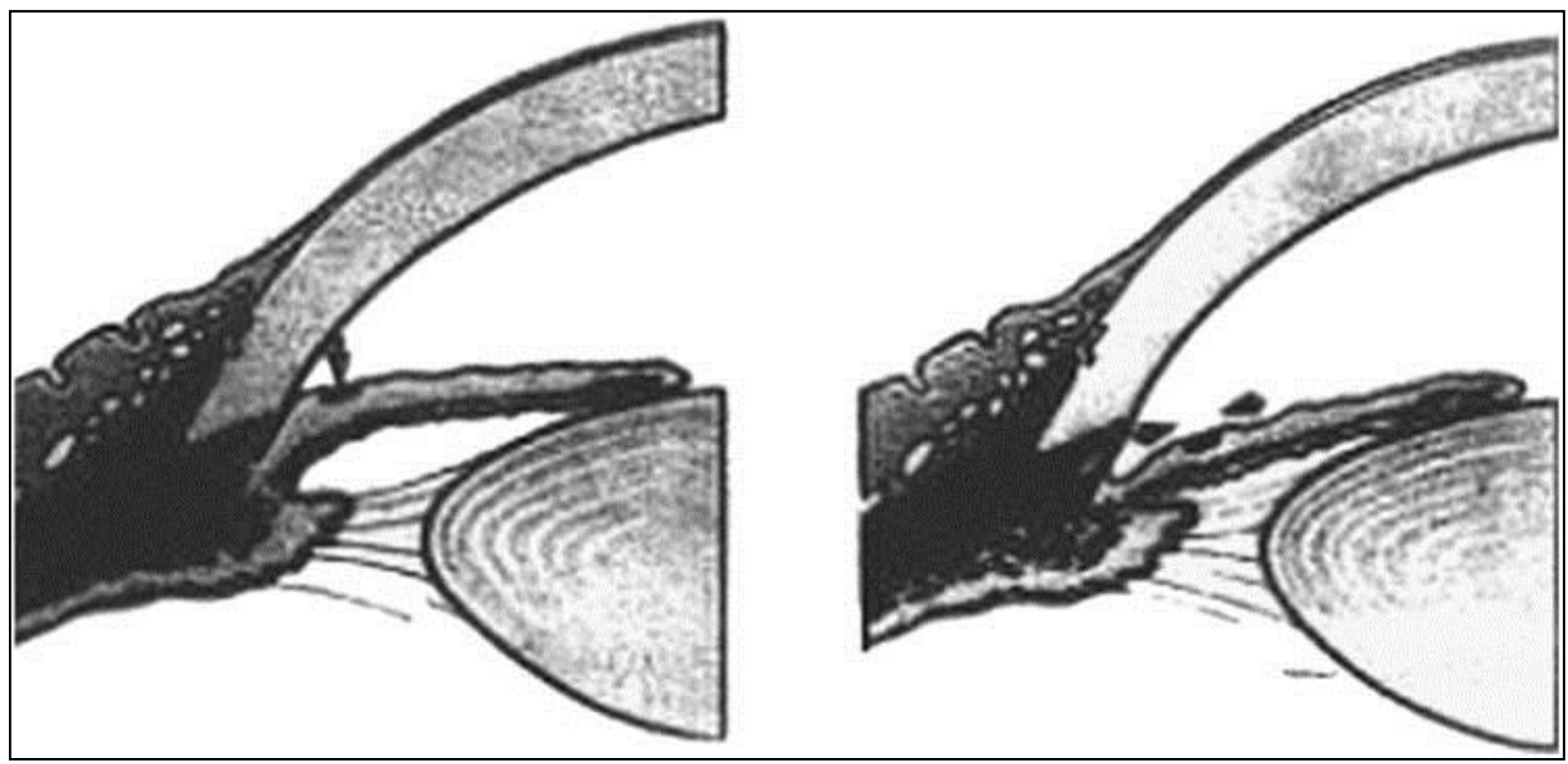

Fig. (4). Schematic diagram illustrating how ALPI contracts the peripheral iris stroma, creating a space between the anterior iris surface and the trabecular meshwork, and thereby opening the angle (from 51, with permission, photo by courtesy of Elsevier).

\section{MICROPULSE DIODE LASER TRANSSCLERAL CYCLOPHOTO-COAGULATION (MICROPULSE TSCPC)}

A new TSCPC technology utilizing a micropulse diode laser which allows a more localized treatment with less collateral damage, is becoming popular. MicroPulse technology employs a continuous-wave laser beam followed by longer-duration "off" intervals that allows for thermal relaxation of the tissue, so thermal damage is reduced. Researchers performed MicroPulse TSCPC on 40 eyes of 38 consecutive patients with refractory glaucomas and a relative success of $80 \%$ was achieved at the end of follow-up time. None of the eyes had post-operative hypotony or visual loss [72]. In a recent study comparing the results of MicroPulse and continuous mode diode TSCPC, both were effective in lowering intraocular pressure. The micropulse mode provided a more consistent and predictable effect in lowering intraocular pressure with minimal ocular complications [73]. 


\section{ENDOSCOPIC CYCLOPHOTOCOAGULATION (ECP)}

ECP employs diode laser energy to the ciliary processes via a small fiber optic endoscope. The endoscope is introduced into the eye either through pars plana or limbus, under direct visualization using a video monitor (Fig. 5). ECP potentially decreases the risk of overtreatment and phthisis bulbi compared with the trans-scleral technique [74]. In a group of patients with prior failed treatment of tube shunts, mean IOP decreased from $24.0 \mathrm{mmHg}$ to $15.4 \mathrm{mmHg}$, and glaucoma medication number decreased from 3.2 to 1.5 after 1 year [75]. ECP can be combined with cataract surgery in patients with less advanced glaucoma. A study combining ECP with phacoemulsification found a significant IOP decrease at all time points after 35 months. The mean IOP was reduced from $23.1 \mathrm{mmHg}$ at baseline to $12.3 \mathrm{mmHg}$ at final visit [76]. Complications of ECP included immediate IOP spikes, anterior chamber inflammation, cystoid macular edema, hypotony, phthisis, choroidal hemorrhages, retinal detachments and fibrin deposition in the anterior chamber [77].

\section{LASER ASSISTED DEEP SCLERECTOMY}

A manual procedure of nonpenetrating deep sclerectomy is an alternative to penetrate trabeculectomies that offers low postoperative complications, however, this procedure is difficult to perform. With the aim of simplifying the manual deep sclerectomy procedure, various lasers have been suggested, including $\mathrm{CO}_{2}$, excimer and erbium:YAG lasers [78]. The operation starts with the manual creation of a superficial flap and then repeated laser applications. This causes progressive ablation of thin layers of deep scleral tissue until aqueous percolation is achieved.

Klink et al. reported a $83.3 \%$ complete success rate with erbium:YAG laser $(\mathrm{IOP}<$ or $=21 \mathrm{mmHg}+\mathrm{IOP}$ reduction $>$ or $=20 \%$ without glaucoma medication) at 3 months and a $50 \%$ success rate at 12 and 50.5 months. The number of glaucoma medications were reduced from 3.07+/-0.92 preoperatively to $1.14+/-1.41$ at 50.5 months postoperatively. $\mathrm{CO}_{2}$ laser-assisted deep sclerectomy was found to be a feasible, safe and effective procedure [79, 80]. The preoperative IOP of $27.3 \pm 4.2 \mathrm{mmHg}($ mean $\pm \mathrm{SD})$ dropped to $15.0 \pm 3.7 \mathrm{mmHg}$ after 6 months and to $16.6 \pm 3.4 \mathrm{mmHg}$ after $12 \mathrm{months}$. The complete success rate after 12 months was $45.5 \%$, whereas qualified success was 90.9\% [81]. An excimer laser is capable of dissecting the deep lamella without thermal damage, resulting in a more regular and smoother surface [78].

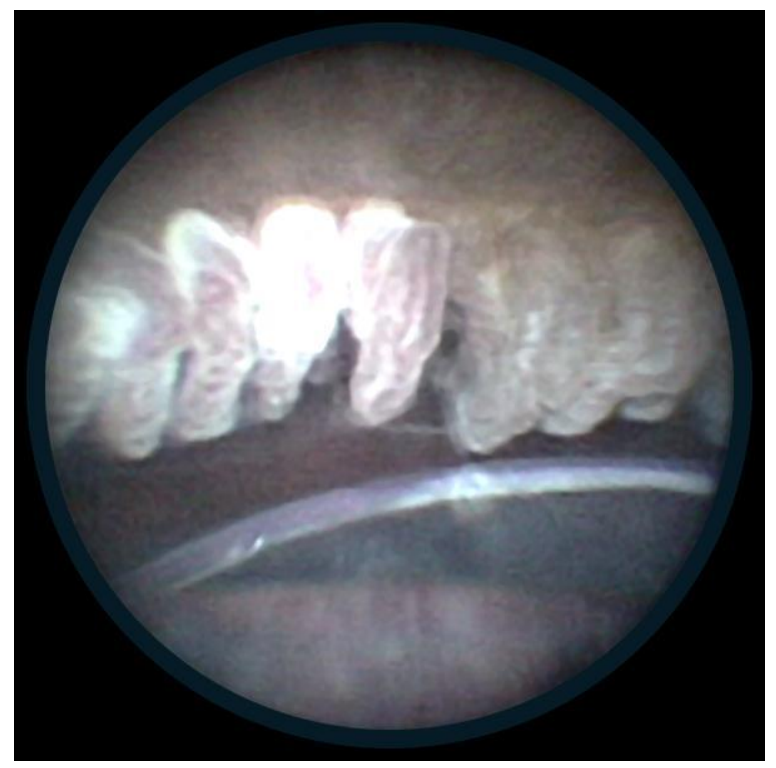

Fig. (5). Shrinkage of ciliary processes during Endoscopic Cyclo-photocoagulation application (photo courtesy of Endo Optiks ${ }^{\circledR}$ ).

\section{CONCLUSION}

Recent studies suggest that laser trabeculoplasty, mainly SLT, may be employed as an initial therapy in patients with mild to moderate open angle glaucoma or ocular hypertension. Good candidates for this treatment strategy include patients with poor adherence of medical therapy, those suffering from ocular surface disease and where cost of medications may be an issue.

New laser technologies, such as MDLT, ELT, TLT and PLT are currently under investigation. Pilot studies 
comparing these laser modalities with SLT or ALT suggest potential advantages, such as improved safety profile and greater efficacy. To date, SLT remains the mainstay of laser trabeculoplasty procedures.

TCP is an effective treatment that carries potential risks. The introduction of ECP, done either alone or in combination with cataract surgery, allows a more controlled cyclophotocoagulation under direct visualization, and thus may carry fewer risks compared with TCP. The pursuit after a safe and effective laser procedure that would provide long-lasting IOP lowering effect is still ongoing.

\section{CONFLICT OF INTEREST}

The authors confirm that this article content has no conflict of interest.

\section{ACKNOWLEDGEMENTS}

Declared none.

\section{REFERENCES}

[1] Wise JB, Witter SL. Argon laser therapy for open-angle glaucoma. A pilot study. Arch Ophthalmol 1979; 97(2): 319-22. [http://dx.doi.org/10.1001/archopht.1979.01020010165017] [PMID: 575877]

[2] Bylsma SS, Samples JR, Acott TS, Van Buskirk EM. Trabecular cell division after argon laser trabeculoplasty. Arch Ophthalmol 1988; 106(4): 544-7.

[http://dx.doi.org/10.1001/archopht.1988.01060130590044] [PMID: 3355425]

[3] Wilensky JT, Weinreb RN. Low-dose trabeculoplasty. Am J Ophthalmol 1983; 95(4): 423-6. [http://dx.doi.org/10.1016/0002-9394(83)90259-3] [PMID: 6837684]

[4] Stein JD, Challa P. Mechanisms of action and efficacy of argon laser trabeculoplasty and selective laser trabeculoplasty. Curr Opin Ophthalmol 2007; 18(2): 140-5. [http://dx.doi.org/10.1097/ICU.0b013e328086aebf] [PMID: 17301616]

[5] Samples JR, Singh K, Lin SC, et al. Laser trabeculoplasty for open-angle glaucoma: a report by the american academy of ophthalmology. Ophthalmology 2011; 118(11): 2296-302. [http://dx.doi.org/10.1016/j.ophtha.2011.04.037] [PMID: 21849211]

[6] Shingleton BJ, Richter CU, Dharma SK, et al. Long-term efficacy of argon laser trabeculoplasty. A 10-year follow-up study. Ophthalmology 1993; 100(9): 1324-9.

[http://dx.doi.org/10.1016/S0161-6420(93)31480-6] [PMID: 8371919]

[7] The Glaucoma laser trial (GLT). 2. Results of argon laser trabeculoplasty versus topical medicines. The glaucoma laser Trial research group. Ophthalmology 1990; 97: 1403-13.

[PMID: 2255512]

[8] Agarwal HC, Sihota R, Das C, Dada T. Role of argon laser trabeculoplasty as primary and secondary therapy in open angle glaucoma in Indian patients. Br J Ophthalmol 2002; 86(7): 733-6.

[http://dx.doi.org/10.1136/bjo.86.7.733] [PMID: 12084739]

[9] Rosenblatt MA, Luntz MH. Intraocular pressure rise after argon laser trabeculoplasty. Br J Ophthalmol 1987; 71(10): 772-5. [http://dx.doi.org/10.1136/bjo.71.10.772] [PMID: 3676148]

[10] The Glaucoma Laser Trial (GLT) and glaucoma laser trial follow-up study: 7. Results. Am J Ophthalmol 1995; 120(6): 718-31. [http://dx.doi.org/10.1016/S0002-9394(14)72725-4] [PMID: 8540545]

[11] Latina MA, Park C. Selective targeting of trabecular meshwork cells: in vitro studies of pulsed and CW laser interactions. Exp Eye Res 1995; 60(4): 359-71.

[http://dx.doi.org/10.1016/S0014-4835(05)80093-4] [PMID: 7789416]

[12] Scuderi GL, Pasquale N. Laser therapies for glaucoma: new frontiers. Prog Brain Res 2008; 173: 225-36. [http://dx.doi.org/10.1016/S0079-6123(08)01116-3] [PMID: 18929112]

[13] Kramer TR, Noecker RJ. Comparison of the morphologic changes after selective laser trabeculoplasty and argon laser trabeculoplasty in human eye bank eyes. Ophthalmology 2001; 108(4): 773-9.

[http://dx.doi.org/10.1016/S0161-6420(00)00660-6] [PMID: 11297496]

[14] Damji KF, Bovell AM, Hodge WG, et al. Selective laser trabeculoplasty versus argon laser trabeculoplasty: results from a 1-year randomised clinical trial. Br J Ophthalmol 2006; 90(12): 1490-4. [http://dx.doi.org/10.1136/bjo.2006.098855] [PMID: 16899528]

[15] Best UP, Domack H, Schmidt V. [Pressure reduction after selective laser trabeculoplasty with two different laser systems and after argon laser trabeculoplasty--a controlled prospective clinical trial on 284 eyes]. Klin Monatsbl Augenheilkd 2007; 224(3): 173-9. [http://dx.doi.org/10.1055/s-2007-963014] [PMID: 17385117]

[16] Martinez-de-la-Casa JM, Garcia-Feijoo J, Castillo A, et al. Selective vs argon laser trabeculoplasty: hypotensive efficacy, anterior chamber 
inflammation, and postoperative pain. Eye (Lond) 2004; 18(5): 498-502. [http://dx.doi.org/10.1038/sj.eye.6700695] [PMID: 15131681]

[17] Latina MA, Sibayan SA, Shin DH, Noecker RJ, Marcellino G. Q-switched 532-nm Nd:YAG laser trabeculoplasty (selective laser trabeculoplasty): a multicenter, pilot, clinical study. Ophthalmology 1998; 105(11): 2082-8. [http://dx.doi.org/10.1016/S0161-6420(98)91129-0] [PMID: 9818610]

[18] El Mallah MK, Walsh MM, Stinnett SS, Asrani SG. Selective laser trabeculoplasty reduces mean IOP and IOP variation in normal tension glaucoma patients. Clin Ophthalmol 2010; 4: 889-93. [http://dx.doi.org/10.2147/OPTH.S11787] [PMID: 20714367]

[19] Bozkurt E, Kara N, Yazici AT, et al. Prophylactic selective laser trabeculoplasty in the prevention of intraocular pressure elevation after intravitreal triamcinolone acetonide injection. Am J Ophthalmol 2011; 152(6): 976-981.e2. [http://dx.doi.org/10.1016/j.ajo.2011.05.027] [PMID: 21861972]

[20] Hong BK, Winer JC, Martone JF, Wand M, Altman B, Shields B. Repeat selective laser trabeculoplasty. J Glaucoma 2009; 18(3): 180-3. [http://dx.doi.org/10.1097/IJG.0b013e31817eee0b] [PMID: 19295367]

[21] Russo V, Barone A, Cosma A, Stella A, Delle Noci N. Selective laser trabeculoplasty versus argon laser trabeculoplasty in patients with uncontrolled open-angle glaucoma. Eur J Ophthalmol 2009; 19(3): 429-34. [PMID: 19396790]

[22] Khouri AS, Lin J, Berezina TL, Maltzman B, Fechtner RD. Repeat selective laser trabeculoplasty can be effective in eyes with initial modest response. Middle East Afr J Ophthalmol 2014; 21(3): 205-9. [http://dx.doi.org/10.4103/0974-9233.134668] [PMID: 25100902]

[23] Lee R, Hutnik CM. Projected cost comparison of selective laser trabeculoplasty versus glaucoma medication in the Ontario Health Insurance Plan. Can J Ophthalmol 2006; 41(4): 449-56 [http://dx.doi.org/10.1016/S0008-4182(06)80006-2] [PMID: 16883360]

[24] Seider MI, Keenan JD, Han Y. Cost of selective laser trabeculoplasty vs topical medications for glaucoma. Arch Ophthalmol 2012; 130(4): 529-30. [http://dx.doi.org/10.1001/archophthalmol.2012.355] [PMID: 22491929]

[25] Melamed S, Ben Simon GJ, Levkovitch-Verbin H. Selective laser trabeculoplasty as primary treatment for open-angle glaucoma: a prospective, nonrandomized pilot study. Arch Ophthalmol 2003; 121(7): 957-60. [http://dx.doi.org/10.1001/archopht.121.7.957] [PMID: 12860797]

[26] McIlraith I, Strasfeld M, Colev G, Hutnik CM. Selective laser trabeculoplasty as initial and adjunctive treatment for open-angle glaucoma. J Glaucoma 2006; 15(2): 124-30.

[http://dx.doi.org/10.1097/00061198-200604000-00009] [PMID: 16633226]

[27] Nagar M, Ogunyomade A, O’Brart DP, Howes F, Marshall J. A randomised, prospective study comparing selective laser trabeculoplasty with latanoprost for the control of intraocular pressure in ocular hypertension and open angle glaucoma. Br J Ophthalmol $2005 ; 89(11)$ : $1413-7$. [http://dx.doi.org/10.1136/bjo.2004.052795] [PMID: 16234442]

[28] Katz LJ, Steinmann WC, Kabir A, Molineaux J, Wizov SS, Marcellino G. Selective laser trabeculoplasty versus medical therapy as initial treatment of glaucoma: a prospective, randomized trial. J Glaucoma 2012; 21(7): 460-8. [http://dx.doi.org/10.1097/IJG.0b013e318218287f] [PMID: 21543992]

[29] Ingvoldstad D, Krishna R, Willoughby L. Micropulse diode laser trabeculoplasty versus argon laser trabeculoplasty in the treatment of open angle glaucoma. Invest Ophthalmol Vis Sci 2005; 46: 123.

[30] Rantala E, Välimäki J. Micropulse diode laser trabeculoplasty -- 180-degree treatment. Acta Ophthalmol 2012; 90(5): 441-4. [http://dx.doi.org/10.1111/j.1755-3768.2010.02026.x] [PMID: 21054817]

[31] Fudemberg SJ, Myers JS, Katz LJ. Trabecular meshwork tissue examination with scanning electron microscopy: a comparison of micropulse diode laser (MLT), selective laser (SLT), and argon laser (ALT) trabeculoplasty in human cadaver tissue. Invest Ophthalmol Vis Sci 2008; 49: 1236 .

[32] Fea AM, Bosone A, Rolle T, Brogliatti B, Grignolo FM. Micropulse diode laser trabeculoplasty (MDLT): A phase II clinical study with 12 months follow-up. Clin Ophthalmol 2008; 2(2): 247-52. [http://dx.doi.org/10.2147/OPTH.S2303] [PMID: 19668712]

[33] Detry-Morel M, Muschart F, Pourjavan S. Micropulse diode laser (810 nm) versus argon laser trabeculoplasty in the treatment of open-angle glaucoma: comparative short-term safety and efficacy profile. Bull Soc Belge Ophtalmol 2008; (308): 21-8. [PMID: 18700451]

[34] Sellem E. News in trabeculoplasty. J Fr Ophtalmol 2008; 31: 2s78-81.

[35] Goldenfeld M, Melamed S, Simon G, Ben Simon GJ. Titanium:sapphire laser trabeculoplasty versus argon laser trabeculoplasty in patients with open-angle glaucoma. Ophthalmic Surg Lasers Imaging 2009; 40(3): 264-9. [http://dx.doi.org/10.3928/15428877-20090430-07] [PMID: 19485290]

[36] Blumenkranz MS, Yellachich D, Andersen DE, et al. Semiautomated patterned scanning laser for retinal photocoagulation. Retina 2006; 26(3): 370-6. [http://dx.doi.org/10.1097/00006982-200603000-00024] [PMID: 16508446] 
[37] Lee JY, Ha SY, Paik HJ, Kwon KY, Kim YY. Morphologic changes in trabecular meshwork after patterned and argon laser trabeculoplasty in cats. Curr Eye Res 2014; 39(9): 908-16. [http://dx.doi.org/10.3109/02713683.2014.884596] [PMID: 24558951]

[38] Turati M, Gil-Carrasco F, Morales A, et al. Patterned laser trabeculoplasty. Ophthalmic Surg Lasers Imaging 2010; 41(5): 538-45. [http://dx.doi.org/10.3928/15428877-20100910-02] [PMID: 20968276]

[39] Fleck BW, Wright E, Fairley EA. A randomised prospective comparison of operative peripheral iridectomy and Nd:YAG laser iridotomy treatment of acute angle closure glaucoma: 3 year visual acuity and intraocular pressure control outcome. Br J Ophthalmol 1997; 81(10): 884-8.

[http://dx.doi.org/10.1136/bjo.81.10.884] [PMID: 9486031]

[40] Özkök A, Tamçelik N, Cicik E, Çömlekoğlu DU. Laser applications on iris for treatment of glaucoma. Turk J Ophthalmol 2013; 43: 190-4.

[41] Zabel RW, MacDonald IM, Mintsioulis G. Corneal endothelial decompensation after argon laser iridotomy. Can J Ophthalmol 1991; 26(7): 367-73. [PMID: 1764642]

[42] Lim L, Seah SK, Lim AS. Comparison of argon laser iridotomy and sequential argon laser and Nd:YAG laser iridotomy in dark irides Ophthalmic Surg Lasers 1996; 27(4): 285-8.

[PMID: 8705743]

[43] de Silva DJ, Day AC, Bunce C, Gazzard G, Foster PJ. Randomised trial of sequential pretreatment for Nd:YAG laser iridotomy in dark irides. Br J Ophthalmol 2012; 96(2): 263-6. [http://dx.doi.org/10.1136/bjo.2010.200030] [PMID: 21515562]

[44] Chung RS, Guan AE. Unusual visual disturbance following laser peripheral iridotomy for intermittent angle closure glaucoma. Graefes Arch Clin Exp Ophthalmol 2006; 244(4): 532-3. [http://dx.doi.org/10.1007/s00417-005-0129-x] [PMID: 16228219]

[45] Spaeth GL, Idowu O, Seligsohn A, et al. The effects of iridotomy size and position on symptoms following laser peripheral iridotomy. J Glaucoma 2005; 14(5): 364-7.

[http://dx.doi.org/10.1097/01.ijg.0000177213.31620.02] [PMID: 16148584]

[46] Murphy PH, Trope GE. Monocular blurring. A complication of YAG laser iridotomy. Ophthalmology 1991; 98(10): 1539-42. [http://dx.doi.org/10.1016/S0161-6420(91)32091-8] [PMID: 1961641]

[47] Vera V, Naqi A, Belovay GW, Varma DK, Ahmed II. Dysphotopsia after temporal versus superior laser peripheral iridotomy: a prospective randomized paired eye trial. Am J Ophthalmol 2014; 157(5): 929-35. [http://dx.doi.org/10.1016/j.ajo.2014.02.010] [PMID: 24531024]

[48] Lam DS, Leung DY, Tham CC, et al. Randomized trial of early phacoemulsification versus peripheral iridotomy to prevent intraocular pressure rise after acute primary angle closure. Ophthalmology 2008; 115(7): 1134-40. [http://dx.doi.org/10.1016/j.ophtha.2007.10.033] [PMID: 18164064]

[49] Husain R, Gazzard G, Aung T, et al. Initial management of acute primary angle closure: a randomized trial comparing phacoemulsification with laser peripheral iridotomy. Ophthalmology 2012; 119(11): 2274-81.

[http://dx.doi.org/10.1016/j.ophtha.2012.06.015] [PMID: 22885123]

[50] Azuara-Blanco A, Burr JM, Cochran C, et al. The effectiveness of early lens extraction with intraocular lens implantation for the treatment of primary angle-closure glaucoma (EAGLE): study protocol for a randomized controlled trial. Trials 2011; 12 : 133. [http://dx.doi.org/10.1186/1745-6215-12-133] [PMID: 21605352]

[51] Ritch R, Tham CC, Lam DS. Argon laser peripheral iridoplasty (ALPI): an update. Surv Ophthalmol 2007; 52(3): $279-88$. [http://dx.doi.org/10.1016/j.survophthal.2007.02.006] [PMID: 17472803]

[52] Lam DS, Lai JS, Tham CC, Chua JK, Poon AS. Argon laser peripheral iridoplasty versus conventional systemic medical therapy in treatment of acute primary angle-closure glaucoma : a prospective, randomized, controlled trial. Ophthalmology 2002; 109(9): 1591-6. [http://dx.doi.org/10.1016/S0161-6420(02)01158-2] [PMID: 12208703]

[53] Lai JS, Tham CC, Chua JK, et al. To compare argon laser peripheral iridoplasty (ALPI) against systemic medications in treatment of acute primary angle-closure: mid-term results. Eye (Lond) 2006; 20(3): 309-14. [http://dx.doi.org/10.1038/sj.eye.6701867] [PMID: 16021197]

[54] Tham CC, Lai JS, Poon AS, et al. Immediate argon laser peripheral iridoplasty (ALPI) as initial treatment for acute phacomorphic angleclosure (phacomorphic glaucoma) before cataract extraction: a preliminary study. Eye (Lond) 2005; 19(7): 778-83 [http://dx.doi.org/10.1038/sj.eye.6701651] [PMID: 15359230]

[55] Ritch R, Tham CC, Lam DS. Long-term success of argon laser peripheral iridoplasty in the management of plateau iris syndrome. Ophthalmology 2004; 111(1): 104-8. [http://dx.doi.org/10.1016/j.ophtha.2003.05.001] [PMID: 14711720]

[56] Espana EM, Ioannidis A, Tello C, Liebmann JM, Foster P, Ritch R. Urrets-Zavalia syndrome as a complication of argon laser peripheral iridoplasty. Br J Ophthalmol 2007; 91(4): 427-9. [http://dx.doi.org/10.1136/bjo.2006.105098] [PMID: 16987896] 
[57] Tam DY, Barnebey HS, Ahmed II II. Nd: YAG laser goniopuncture: indications and procedure. J Glaucoma 2013; 22(8): 620-5. [http://dx.doi.org/10.1097/IJG.0b013e31824d512a] [PMID: 23685913]

[58] Meyer JJ, Lawrence SD. What's new in laser treatment for glaucoma? Curr Opin Ophthalmol 2012; 23(2): $111-7$. [http://dx.doi.org/10.1097/ICU.0b013e32834f1887] [PMID: 22186007]

[59] Anand N, Pilling R. Nd:YAG laser goniopuncture after deep sclerectomy: outcomes. Acta Ophthalmol 2010; 88(1): 110-5. [http://dx.doi.org/10.1111/j.1755-3768.2008.01494.x] [PMID: 19302078]

[60] Alp MN, Yarangumeli A, Koz OG, Kural G. Nd:YAG laser goniopuncture in viscocanalostomy: penetration in non-penetrating glaucoma surgery. Int Ophthalmol 2010; 30(3): 245-52. [http://dx.doi.org/10.1007/s10792-009-9312-0] [PMID: 19479194]

[61] Walker R, Specht H. [Theoretical and physical aspects of excimer laser trabeculotomy (ELT) ab interno with the AIDA laser with a wave length of $308 \mathrm{~mm}$ ]. Biomed Tech (Berl) 2002; 47(5): 106-10. [http://dx.doi.org/10.1515/bmte.2002.47.5.106] [PMID: 12090137]

[62] Babighian S, Rapizzi E, Galan A. Efficacy and safety of ab interno excimer laser trabeculotomy in primary open-angle glaucoma: two years of follow-up. Ophthalmologica 2006; 220(5): 285-90. [http://dx.doi.org/10.1159/000094616] [PMID: 16954703]

[63] Babighian S, Caretti L, Tavolato M, Cian R, Galan A. Excimer laser trabeculotomy vs 180 degrees selective laser trabeculoplasty in primary open-angle glaucoma. A 2-year randomized, controlled trial. Eye (Lond) 2010; 24(4): 632-8. [http://dx.doi.org/10.1038/eye.2009.172] [PMID: 19590523]

[64] Wilmsmeyer S, Philippin H, Funk J. Excimer laser trabeculotomy: a new, minimally invasive procedure for patients with glaucoma. Graefes Arch Clin Exp Ophthalmol 2006; 244(6): 670-6. [http://dx.doi.org/10.1007/s00417-005-0136-y] [PMID: 16235060]

[65] Töteberg-Harms M, Ciechanowski PP, Hirn C, Funk J. [One-year results after combined cataract surgery and excimer laser trabeculotomy for elevated intraocular pressure]. Ophthalmologe 2011; 108(8): 733-8. [PMID: 21359550]

[66] Pastor SA, Singh K, Lee DA, et al. Cyclophotocoagulation: a report by the American Academy of Ophthalmology. Ophthalmology 2001; 108(11): 2130-8.

[http://dx.doi.org/10.1016/S0161-6420(01)00889-2] [PMID: 11713091]

[67] Vucicevic ZM, Tsou KC, Nazarian IH, Scheie HG, Burns WP. A cytochemical approach to the laser coagulation of the ciliary body. Bibl Ophthalmol 1969; 79: 467-78. [PMID: 5388264]

[68] Albahlal A, Al Dhibi H, Al Shahwan S, Khandekar R, Edward DP. Sympathetic ophthalmia following diode laser cyclophotocoagulation. Br J Ophthalmol 2014; 98(8): 1101-6. [http://dx.doi.org/10.1136/bjophthalmol-2013-304257] [PMID: 24711656]

[69] Aujla JS, Lee GA, Vincent SJ, Thomas R. Incidence of hypotony and sympathetic ophthalmia following trans-scleral cyclophotocoagulation for glaucoma and a report of risk factors. Clin Experiment Ophthalmol 2013; 41(8): 761-72. [http://dx.doi.org/10.1111/ceo.12088] [PMID: 23433313]

[70] Pucci V, Tappainer F, Borin S, Bellucci R. Long-term follow-up after transscleral diode laser photocoagulation in refractory glaucoma. Ophthalmologica 2003; 217(4): 279-83. [http://dx.doi.org/10.1159/000070635] [PMID: 12792134]

[71] Schlote T, Derse M, Rassmann K, Nicaeus T, Dietz K, Thiel HJ. Efficacy and safety of contact transscleral diode laser cyclophotocoagulation for advanced glaucoma. J Glaucoma 2001; 10(4): 294-301. [http://dx.doi.org/10.1097/00061198-200108000-00009] [PMID: 11558814]

[72] Tan AM, Chockalingam M, Aquino MC, Lim ZI, See JL, Chew PT. Micropulse transscleral diode laser cyclophotocoagulation in the treatment of refractory glaucoma. Clin Experiment Ophthalmol 2010; 38(3): 266-72. [PMID: 20447122]

[73] Aquino MC, Barton K, Tan AM, et al. Micropulse versus continuous wave transscleral diode cyclophotocoagulation in refractory glaucoma: a randomized exploratory study. Clin Experiment Ophthalmol 2015; 43(1): 40-6. [http://dx.doi.org/10.1111/ceo.12360] [PMID: 24811050]

[74] Lin SC. Endoscopic and transscleral cyclophotocoagulation for the treatment of refractory glaucoma. J Glaucoma 2008; 17(3): 238-47. [http://dx.doi.org/10.1097/IJG.0b013e31815f2539] [PMID: 18414112]

[75] Francis BA, Kawji AS, Vo NT, Dustin L, Chopra V. Endoscopic cyclophotocoagulation (ECP) in the management of uncontrolled glaucoma with prior aqueous tube shunt. J Glaucoma 2011; 20(8): 523-7. [PMID: 21048513]

[76] Lima FE, Carvalho DM, Avila MP. [Phacoemulsification and endoscopic cyclophotocoagulation as primary surgical procedure in coexisting cataract and glaucoma]. Arq Bras Oftalmol 2010; 73(5): 419-22. [http://dx.doi.org/10.1590/S0004-27492010000500006] [PMID: 21225125] 
[77] Ishida K. Update on results and complications of cyclophotocoagulation. Curr Opin Ophthalmol 2013; 24(2): 102-10. [http://dx.doi.org/10.1097/ICU.0b013e32835d9335] [PMID: 23313903]

[78] Klink T, Schlunck G, Lieb W, Klink J, Grehn F. $\mathrm{CO}_{2}$, excimer and erbium:YAG laser in deep sclerectomy. Ophthalmologica 2008; 222(2): 74-80.

[http://dx.doi.org/10.1159/000112622] [PMID: 18303226]

[79] Assia EI, Rotenstreich Y, Barequet IS, Apple DJ, Rosner M, Belkin M. Experimental studies on nonpenetrating filtration surgery using the $\mathrm{CO}_{2}$ laser. Graefes Arch Clin Exp Ophthalmol 2007; 245(6): 847-54. [http://dx.doi.org/10.1007/s00417-006-0413-4] [PMID: 17058094]

[80] Ton Y, Geffen N, Kidron D, Degani J, Assia EI. $\mathrm{CO}_{2}$ laser-assisted sclerectomy surgery part I: concept and experimental models. J Glaucoma 2012; 21(2): 135-40. [PMID: 21423033]

[81] Skaat A, Goldenfeld M, Cotlear D, Melamed S. CO 2 laser-assisted deep sclerectomy in glaucoma patients. J Glaucoma 2014; 23(3): 179-84. [http://dx.doi.org/10.1097/IJG.0b013e3182707406] [PMID: 24590117]

Received: July 26, 2015 Revised: August 18, 2015

Accepted: August 18, 2015

(C) Ekici et al.; Licensee Bentham Open.

This is an open access article licensed under the terms of the Creative Commons Attribution-Non-Commercial 4.0 International Public License (CC BY-NC 4.0) (https://creativecommons.org/licenses/by-nc/4.0/legalcode), which permits unrestricted, non-commercial use, distribution and reproduction in any medium, provided the work is properly cited. 